NASA Technical Memorandum 107502

IECEC-97235

\title{
Mir Cooperative Solar Array Flight Performance Data and Computational Analysis
}

Thomas W. Kerslake and David J. Hoffman

Lewis Research Center

Cleveland, Ohio

Prepared for the

32nd Intersociety Energy Conversion Engineering Conference cosponsored by AIChE, ANS, SAE, AIAA, ASME, and IEEE Honolulu, Hawaii, July 27-August 1, 1997

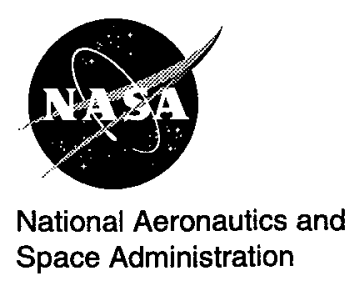




\title{
MIR COOPERATIVE SOLAR ARRAY FLIGHT PERFORMANCE DATA AND COMPUTATIONAL ANALYSIS
}

\author{
Thomas W. Kerslake \\ NASA Lewis Research Center \\ Cleveland, Ohio 44135 \\ 216-433-5373 (voice) ; 216-433-2995 (fax) \\ David J. Hoffman \\ NASA Lewis Research Center \\ Cleveland, Ohio 44135 \\ 216-433-2445 (voice) ; 216-433-2995 (fax)
}

\begin{abstract}
The Mir Cooperative Solar Array (MCSA) was developed jointly by the United States (US) and Russia to provide approximately $6 \mathrm{~kW}$ of photovoltaic power to the Russian space station Mir. The MCSA was launched to Mir in November 1995 and installed on the Kvant-1 module in May 1996. Since the MCSA photovoltaic panel modules (PPMs) are nearly identical to those of the International Space Station (ISS) photovoltaic arrays, MCSA operation offered an opportunity to gather multi-year performance data on this technology prior to its implementation on ISS. Two specially designed test sequences were executed in June and December 1996 to measure MCSA performance. Each test period encompassed 3 orbital revolutions whereby the current produced by the MCSA channels was measured. The temperature of MCSA PPMs was also measured. To better interpret the MCSA flight data, a dedicated FORTRAN computer code was developed to predict the detailed thermalelectrical performance of the MCSA. Flight data compared very favorably with computational performance predictions. This indicated that the MCSA electrical performance was fully meeting pre-flight expectations. There were no measurable indications of unexpected or precipitous MCSA performance degradation due to contamination or other causes after 7 months of operation on orbit. Power delivered to the Mir bus was lower than desired as a consequence of the retrofitted power distribution cabling. The strong correlation of experimental and computational results further bolsters the confidence level of performance codes used in critical ISS electric power forecasting. In this paper, MCSA flight performance tests are described as well as the computational modeling behind the performance predictions.
\end{abstract}

\section{INTRODUCTION}

The objective of the Mir Cooperative Array (MCSA) project was to increase the electrical power available to the 10-year old Russian space station Mir (Housten et al., 1996). The added power is extending Mir's useful life and supporting
U.S. experiments conducted under the International Space Station (ISS), Phase I United States (US)/Russian program. This objective was met by replacing an existing, degraded photovoltaic array with a new array developed cooperatively by the U.S. and Russia using existing hardware to the maximum extent. After final assembly in Russia, the MCSA was shipped to the NASA Kennedy Space Center (KSC) in the summer of 1995. As part of the pre-launch checkout activities, the MCSA underwent dark electrical testing which confirmed the solar array cells and circuitry were undamaged as a result of transportation and ground handling (Kerslake, et al., 1997). The MCSA was launched to Mir by the space shuttle Atlantis during the November 1995 STS-74 mission and installed on the Kvant-1 module in May 1996.

A second program objective was to reduce technical risk for the ISS Phase II Program since MCSA performance data are directly applicable to ISS arrays which employ the same US solar array technology. MCSA operation offered an opportunity to gather multi-year performance data on the ISS solar array technology prior to its implementation on ISS in 1998. Also, by correlating the test data with computational predictions, ISS Electrical Power System (EPS) performance codes (Hojnicki, 1991 and Fincannon, et al. 1996) could be further validated. These codes provide invaluable information to resource managers that plan electric power utilization for ISS mission operations.

To this end, on-orbit performance data were gathered in June 1996 and December 1996. This paper documents these data and the comparison with computational predictions derived from a modified version of the NASA Lewis Research Center (LeRC) power system analysis code "SPACE/ECAPS" (Hojnicki, et al. 1992 and 1993 and Kerslake, et al., 1993).

\section{DESCRIPTION OF MCSA HARDWARE AND INSTALLATION}

The MCSA consists of 84 Photovoltaic Panel Modules (PPMs) (Wilkinson, 1995 and Chau and Brisco, 1995) mounted in pairs (end-to-end) in 42 Russian Module Frame 
Assemblies or panels. Figure 1 is a mission STS-79 photograph of the MCSA, shown in the foreground, installed on the Mir Kvant-1 module -Z-axis solar array pointing system drive. Figure 2 depicts the Mir coordinate axes and module names. The MCSA has a deployed length of $18 \mathrm{~m}$, a width of $2.7 \mathrm{~m}$, a mass (including deployment mechanism) of $517 \mathrm{~kg}$ and a beginning-of-life power of approximately $6 \mathrm{~kW}$. The deployed angle between panels is $14^{\circ}$ on average.

Each PPM, shown in Figure 3, is a collection of 80 seriesconnected, $8 \mathrm{~cm} \times 8 \mathrm{~cm}$, silicon, $\mathrm{n}$ on p solar cells with $15 \%$ average room temperature efficiency. These cells were originally developed for the Space Station Freedom program and will be used on the ISS arrays. The cells are mounted on a flexible polyimide/glass scrim cloth substrate and connected via a copper flat printed circuit (FPC). A by-pass diode is wired in parallel with every 10 cells. In order to fit the PPM into the existing frames, the five cells at each end of the PPM were shortened by $0.5 \mathrm{~cm}$.

PPMs two abreast are wired in parallel to form a panel. Flexible, flat copper circuit (FCC) wiring $1 \mathrm{~cm}$ in width and of various thicknesses runs along both outer edges of the MCSA to connect each panel to the so-called "panel 0" at the base of the MCSA. Panel 0 is an inactive panel that provides weld pads to connect the active panels in parallel and transition to round wire cabling. Panels are parallel connected in groups of 3 or 4 to form current generators (GSs). Thus, each generator has a total of either 6 or 8 PPMs in parallel. There are six generators consisting of $6 \mathrm{PPMs}$ and six generators consisting of 8 PPMs (see Figure 4). A total of four platinum Resistance Temperature Devices (RTDs) were mounted on the back side of panels 2, 5, 7 and 10 of GS 1 and GS 2. The RTDs were positioned coincident with solar cellto-substrate adhesive pads. The adhesive pads provide sufficient thermal conductance to maintain the back temperature within $1^{\circ} \mathrm{C}$ of the front (silicon) temperature of primary interest.

Round cabling from the GS negative weld pads is fed to three 32-pin connectors ( $x 61-63$ ) while those from the positive pads are also fed to three 32-pin connectors (x64-66) (see Figure 5). Cabling runs from the six 32-pin connectors to four 184-pin connectors $(\mathrm{x} 1-\mathrm{x} 4)$. The connectors are physically located at the base structure of the MCSA and serve as the interface to the Mir power distribution cabling network.

Custom electrical power distribution cable sets were constructed to accommodate the larger number of solar array current generators and the increase in electrical current in the MCSA as compared to the typical Russian solar array. These cable sets connected the MCSA to current regulators in the Mir Core module. Cables were run externally from the X1X4, 184-pin connectors at the base of the MCSA along the outside of the Kvant-1 module and entered the pressurized environment at the Mir Core module. The cables consisted of multiple parallel strands of copper wire (circular crosssections between $0.35-1.0 \mathrm{sq} \mathrm{mm}$ ) cross-connected for redundancy. While the longest cable run was 63.15 meters (+GS 4), the average total length of a GS cable set was 48.4 meters. The cables were actually manufactured and installed as two separate sets at two separate times. The first cable set was delivered to Mir in May 1996 when the MCSA was initially deployed. This cable set connected half of the MCSA (GS 1,2, 9-12). The second set was delivered to Mir in December 1996, when the remainder of the MCSA was electrically connected (GS 3-8).
Current regulator output voltage is controlled to $28.5 \pm 0.5$ VDC. The actual bus voltage regulation achieved in operation is substantially better than $\pm 0.5 \mathrm{VDC}$.

\section{MIR FLIGHT ATTITUDE AND ORBIT MECHANICS}

Two multi-orbit test periods were utilized to measure MCSA on-orbit performance. The dates of these test periods were June 20, 1996 and December 19,1996 which are close to the Summer and Winter Solstices, respectively. Table 1 summarizes the Mir flight attitude and orbit information pertinent to these tests. Mir flew solar inertial in a $214 \mathrm{nmi}$ $(400 \mathrm{~km})$ circular Earth orbit inclined $51.6^{\circ}$ and with a 92.5 minute period. Krylov angles fix the Mir station attitude relative to J2000 inertial space (Smith, 1986). These angles are analogous to Euler angles used to fix the attitude of the Space Shuttle Orbiter. These flight attitudes and orbit conditions were chosen to provide the MCSA with optimum solar illumination, i.e. near normal solar incidence and no shadowing. During the December test, a Progress-TM resupply vehicle solar array did cast a narrow shadow on GS 1 (the first 3 active panels) in the longitudinal middle of the MCSA. However, analyses showed that this shadow was not large enough to affect the current output of the PPMs in the vicinity of the shadow.

To point the MCSA at the Sun, the solar array drive is commanded to move to one of the 16 discrete angular zones. The drive stops in the middle of the angular pointing zone with an uncertainty of $\pm 3^{\circ}$. Knowing the solar array drive position and the angles between the Sun vector and the Mir axes measured by onboard Sun sensors, the MCSA solar tracking error was calculated to be $3.8^{\circ} \pm 3^{\circ}$ and $1.6^{\circ} \pm 3^{\circ}$, respectively, for the June and December tests.

\section{INSTRUMENTATION AND TEST PROCEDURES}

Two MCSA performance parameters were measured: generator current and (2) PPM temperature. Currents were measured by the current regulators using magnetic amplifiers with $\pm 5 \%$ accuracy. This resulted in a current measurement error of $\pm 0.5-1$ amps. RTD resistance values were measured using a Wheatstone bridge circuit with $\pm 1 \%$ accuracy. This resulted in temperature measurement error of $+4{ }^{\circ} \mathrm{C} /-3^{\circ} \mathrm{C}$ for maximum PPM temperatures and $\pm 2^{\circ} \mathrm{C}$ for minimum PPM temperatures.

Since direct PPM electrical measurements were not made, the use of a computational performance model becomes very important for properly interpreting the GS current data. The computer model used for this purpose is described in section 5 . PPM temperature measurements in concert with GS current data are also important. The availability of both data sets allows one to better separate temperature-dependent IV performance changes from those induced by environmental degradation, array solar pointing, shadowing, etc.

\subsection{June 1996 Test}

At this date, the first set of power distribution cables were installed to connect MCSA generators GS $1,2,9,10,11$ and 12 . Thus, 38 PPMs out of the total 84 PPMs were connected. Prior to the test orbits, the Mir flight attitude was established to provide optimum solar illumination for the MCSA. The MCSA is paralleled to the same current regulators that are used by the companion array on Kvant-1 and part of the core module array. Thus, over the 3-orbit test sequence, the Mir cosmonaut crew disconnected and sequentially reconnected 
the power supply feeds from the various arrays during the orbital eclipse periods. The sequence of array connections was: Orbit 1 - core array only, Orbit 2 - Core array plus MCSA GS $1,2,9,10$, and Orbit 3 - Core array plus MCSA plus the companion Kvant-1 array. The MCSA currents were derived by differencing the regulator current data of orbits 1 and 2. The current measurement error introduced from this approach was primarily due to orbit-to-orbit variation in environmental heating. Based on current measurements from several independently connected core array generators, this error was estimated to be $\pm 2 \%$. No data were obtained from MCSA GS 11 and 12 which could not be independently disconnected from the companion $K v a n t-1$ array power feeds.

The current and temperature data measured were stored on the Mir data acquisition system for later transmission to the Moscow Mission Control Center. Analog strip chart plots of the telemetry data were reduced by hand to produce current data points at 3-minute intervals and temperature data at 2minute intervals. The temporal precision in aligning orbit 1 and 2 current data sets was estimated to be \pm 1 minute.

\subsection{December 1996 Test}

Like the June test, the Mir flight attitude was established to provide optimum solar illumination for the MCSA during three sequential orbits. However, for this test, the Mir cosmonauts disconnected the MCSA power feeds and reconnected them to dedicated current regulators. This operation was accomplished during the eclipse period prior to the test orbits and provided direct measurements of generator current levels. This also obviated the need for orbit-to-orbit current differencing with its associated uncertainty. All data were stored digitally and much of the data was telemetered directly. This eliminated the data set time uncertainty and reduced the data scatter. As in the June test, no data were obtained from MCSA GS 10, 11 and 12 which could not be physically disconnected from their current regulators for independent measurements. Unfortunately, no RTD temperature data were obtained for the December test. The RTDs failed in an opencircuited condition in November 1996.

\section{COMPUTATIONAL ANALYSIS}

A dedicated FORTRAN computer code was written to predict the MCSA electrical and thermal performance. The computational methodologies are based on those from the LeRC code SPACE/ECAPS (Hojnicki et al., 1993 and Fincannon 1996) used to predict ISS electrical power system performance. The solar array portion of this code was heavily modified to model the MCSA as installed on the Mir space station. Salient features of the MCSA performance modeling are described in the sections below.

\subsection{Orbit Mechanics, Flight Attitude and Solar Pointing}

The SPACE orbit mechanics subroutines calculate circular Earth orbit parameters and can propagate satellite orbits based on a two term Earth geopotential model, i.e. the J2 harmonic, oblateness, is included. Typical inputs include orbit altitude, inclination and mission date. Outputs include orbit period, insolation/eclipse times, solar beta angle, and solar constant. Multiple vehicle flight attitudes can be modeled by specifying the time-dependent Euler rotations of the vehicle about a local-vertical, local-horizontal (LVLH) reference. Torque equilibrium angles may also be specified. A set of orthogonal solar array gimbals is modeled. Solar tracking options include locked, perfect Sun pointing, biased Sun pointing or a random distribution of pointing errors within pre-set limits. For the MCSA on Mir, the biased Sun pointing option was used with fixed pointing errors of $3.8^{\circ}$ and $1.6^{\circ}$, respectively, for the June and December tests. Using the vehicle attitude and solar array tracking information, the code calculates the view factor from the array to the Earth throughout the orbit period. These view factors are used in MCSA radiation heat transfer computations.

\subsection{Heat Transfer}

PPM temperatures are predicted using a transient, finitedifference model of a single solar cell mounted on the polyimide substrate. All cells on a given PPM are then assumed to operate at the same temperature. Temperatures are calculated in fine time resolution throughout the orbit while boundary conditions, heat generation, and electrical power production terms are up-dated 90 times per orbit, i.e. at $\sim 4^{\circ}$ angular increments or $\sim 1$-minute time intervals. Heat inputs to the cell front and/or back sides include: direct solar insolation, Earth albedo flux, Earth infrared (IR) flux and neighboring panel reflected solar flux and emitted IR flux. The solar flux intensity is corrected for MCSA pointing error and non-flatness (the $14^{\circ}$ accordion angle between panels). A small heat input is also provided by ohmic losses in the PPM FPC wiring that interconnects the solar cells. Heat outputs from the cell include electrical power produced and IR radiation to the space sink. Panel front and back side view factors to deep space were reduced by the sum of view factors to Mir surfaces. This implicitly assumes that for radiation heat transfer purposes, the Mir surfaces are operating at the same temperature as the MCSA panels.

\subsection{PPM Current-Voltage Response}

SPACE reads in the current-voltage (IV) parameters measured for each PPM via flash testing. The parameters are short-circuit current (Isc), open-circuit voltage (Voc), maximum power current (Imp) and maximum power voltage (Vmp). Typical values for these parameters measured at $23^{\circ} \mathrm{C}$ are Isc $=2.66$ amps, Voc $=49.7$ volts, $I m p=2.40$ amps and $V m p=38.2$ volts. These parameters are corrected for MCSA orbital operating temperature, solar intensity and Sun pointing accuracy. Degradation factors are also applied to these IV parameters to account for exposure time in the low Earth orbit (LEO) environment. Degradation factors are included for: charged particle radiation, contamination, micrometeoroid/orbital debris (MM/OD) damage, UV darkening, by-pass diode failures and thermal cycling. The adjusted IV parameters are then used in a single diode solar cell model to generate an IV operating curve for each PPM.

Since the solar cells are mounted on a substrate that is transparent to solar wavelength radiation, backside solar cell power production must be considered. Based on flash testing with normal backside illumination, $33 \%$ of the Isc and $25 \%$ of the maximum power, Pmax, is produced when compared to illuminating the front side. Backside flash testing was also performed over a range of incidence angles.

During the MCSA test orbits, PPM back sides were illuminated with albedo fluxes. The PPM backside albedo current production was determined as follows: (1) for each orbital calculation point, the PPM back side albedo flux and equivalent incidence angle was calculated, (2) based on flash 
test data, the Isc-back/Isc-front ratio was determined for the given equivalent incidence angle, (3) the Isc-back/Isc-front ratio was then linearly scaled by the ratio of the albedo flux level to the mission date insolation intensity, (4) the Isc-back was determined by multiplying the Isc-front and the Iscback/Isc-front ratio. The PPM adjusted IV parameters were then determined as follows: (1) Isc was calculated by adding Isc-front and Isc-back, (2) Voc was scaled by the ratio of natural logarithms $\ln$ (Isc front+back / Io) / $\ln$ (Isc front / Io) where Io is the diode saturation current, (3) Imp was scaled by the measured ratio (Pmax-back / Pmax-front) corrected for the albedo flux intensity and (4) Vmp was not changed. The latter is justified by the expectation that Vmp would translate only a small amount along the very steep slope of the PPM solar cell lumped series resistance line (1/Rs) where Rs is $\sim 0.01 \Omega /$ cell.

\subsection{Cable Voltage Drops and Current Regulator}

The resistance of the each panel FCC was measured at ambient temperature with an accuracy of $\pm 1.5 \%$. FCC resistances varied from $\sim 0.1 \Omega$ for panel 1 to $\sim 1 \Omega$ for panel 42 . These resistances were used to calculate FCC voltage drop as a function of the current level with an assumed operating temperature at $60^{\circ} \mathrm{C}$. The resistance of round copper wire cabling from the MCSA panel 0 to the input of the current regulator was calculated based on wire lengths and cross sections provided in cable drawings. The cable sets were modeled as a resistive network consisting of segments and nodes. A subroutine inverted the conductance matrix for each GS cable run resulting in a calculated equivalent resistance for each GS. The portion of the cables in the external space environment was assumed to operate at $60^{\circ} \mathrm{C}$ while the portion in the pressurized environment was set at $30^{\circ} \mathrm{C}$. The average equivalent resistance for the combined positive and negative cables was found to be approximately $0.2 \Omega$.

The current regulator was modeled as 24 parallel legs of a series connected diodes and resistors. The diode voltage drop was calculated based on a single exponential model and an assumed operating temperature of $23^{\circ} \mathrm{C}$.

\subsection{Computation Iterations}

For each of the sunlit orbit computation points, each MCSA generator was selected and analyzed. The code executed nested iterations to solve for: generator current, cabling voltage drops, current regulator voltage drop, panel currents, PPM currents and voltages, and PPM temperatures with an assumed constant current regulator output voltage of 28.5 volts. The convergence criteria were: generator current (0.006 amp), panel current $(0.002 \mathrm{amp})$, PPM current $(0.001$ amp), and PPM power versus temperature iteration (0.008 watt). During eclipse orbit computation points, only PPM temperatures were calculated. Code execution time on a HP Apollo Series 400 work station was approximately 30 minutes to analyze one orbit.

\section{RESULTS}

\subsection{Generator Current Output}

Figure 6 shows typical generator current computational predictions and measured data for GS 9 and 10 obtained in the June test. GS 9 and 10 both have 6 PPMs connected in parallel. Following the 35-minute eclipse period, generator current rose sharply to a peak value near 15 amps as the generators, still cold from the eclipse period, produced current efficiently. Current level fell off toward orbit noon at 65 minutes when the generators experienced the highest Earth albedo and IR fluxes and attained their highest temperature. As Mir proceeded toward orbit sunset at 92.5 minutes, temperatures decreased allowing for a modest current increase. The predictions compared very well with the measured data. The overall temporal shape of the generator current curve was predicted and although there was considerable scatter in the data, the magnitude of predicted currents generally fell within the data error limits.

Figure 7 shows as similar comparison of predicted generator currents and those measured during the December test for GS 1 and 2 at the base of the MCSA. GS 1 has 6 paralleled PPMs while GS 2 has 8 paralleled PPMs. The overall shape of the generator current curve was the same as that obtained in June. The scatter present in the data set was considerably less than that of the June test due to superior test and data acquisition/reduction procedures employed. Again, the predictions fell within the error limits for nearly every data point for GS 2. For GS 1, the current level was underpredicted by approximately 2 amps. The cause for this underprediction was primarily due to an over-prediction in the temperature of panel 1 within GS 1 . This is further discussed in section 6.2. Another favorable comparison of generator current output is shown Figure 8 for GS 6 and 8 located in the middle of the MCSA.

Figure 9 shows the current output measured for GS 2 in June and December. These data sets, as were those of the other generators, were very similar. During the June test, the solar insolation was $6.5 \%$ lower than in December. This allowed the generators to operate about $10^{\circ} \mathrm{C}$ cooler and produce slightly higher current output compared to December. Since the measured current output level correlates well with the available insolation and operating temperature, no precipitous degradation mechanisms (i.e., heavy surface molecular contamination) were detected as a result of the six month, Mir/LEO exposure period from June to December.

\subsection{PPM Operating Temperature}

PPM back side temperature measurements were obtained during the June test. These data and computational predictions for PPMs on panel 1 and 2 are shown in Figure 10 while results for panel 10 are provided in Figure 11. PPM temperatures fell off rapidly during the first 10 minutes of eclipse. For the next 15 minutes centered about orbit midnight, good view factors to Earth and its IR heat flux stabilized the PPM temperature in the $-20^{\circ} \mathrm{C}$ to $-40^{\circ} \mathrm{C}$ range. This was followed by another temperature drop off into the -60 ${ }^{\circ} \mathrm{C}$ to $-70^{\circ} \mathrm{C}$ temperature range attained just prior to orbit sunrise. The computational predictions reproduce this PPM eclipse temperature trend but under-predict temperatures by $-30^{\circ} \mathrm{C}$. This discrepancy was most likely due to simplified modeling of radiant heat transfer between the MCSA PPMs and Mir. For example, the RTD on panel 2 was located near the fold line of panels 1 and 2 . Thus, the measured temperature should be in between the lumped, spatial-average temperature predicted for panel 1 and 2 . Panel radiation heat transfer modeling could be improved in the future if better fidelity eclipse time PPM temperatures were required.

Upon entering sunlight at an orbit time of 35 minutes, the PPMs rapidly heat up for a 7-minute period. The predicted temperatures followed this measured temperature transient 
very well indicating the PPM thermal mass characteristics and heating boundary conditions were properly calculated The predictions continued to match the modest PPM temperature rise measured through orbit noon at 65 minutes. Following orbit noon, predicted temperatures fell off in response to the drop in PPM backside heating from the Earth. The measured temperatures, however, continued to increase and stabilized at $\sim 85^{\circ} \mathrm{C}$ for panel 2 and $\sim 70^{\circ} \mathrm{C}$ for panel 10 . (During the June test, the PPMs on panel 10 (GS 3) were not electrically connected and producing power. Thus, the $\sim 70^{\circ} \mathrm{C}$ peak operating temperatures were about $10^{\circ} \mathrm{C}$ higher than the nominal $\sim 60^{\circ} \mathrm{C}$ operating temperature when the PPMs were producing electrical power. For reference, a $56^{\circ} \mathrm{C}$ operating temperature was assumed for specifying PPM electrical performance characteristics.)

Two plausible causes for the observed PPM temperature behavior are from temporarily elevated MCSA heat fluxes from: (1) localized high Earth albedo and/or (2) locally maximized spacecraft albedo. Variation in MCSA heat flux from these two causes was not modeled. Examination of Figures 6 and 9 revealed that generator current levels stabilized and/or decreased toward the end of the sun period in response to the elevated temperatures. This same effect did not occur in the measured current data taken in December indicating the PPM temperature rise did not take place during the latter half of the sun period.

Panel 1 temperature was not measured but the predicted temperature is shown in Figure 10. Panel 1 exhibits an "inverse" temperature response during the orbit sun period: that is, the temperature is cooler at orbit noon and warmer near the orbit terminators. This behavior is explained by the fact that backside of panel 1 has only a small view factor to the Earth. Thus, panel back side Earth heating fluxes are small and the panel temperature is more effected by front side Earth heat fluxes. These fluxes are maximum at the orbit terminators for a sun-tracking surface. In general, panel 1 temperatures will be over-predicted due to the assumption that panels radiate heat to Mir structures at the same operating temperature. In reality, Mir operating temperatures are close to those of outboard MCSA panels, i.e. in the $\pm 50^{\circ} \mathrm{C}$ range, while those of panel 1 are probably in the $+90^{\circ} \mathrm{C} /-40^{\circ} \mathrm{C}$ range. Therefore, radiative cooling of panel 1 would be underpredicted leading to an over-predicted temperature.

\subsection{PPM Operating Current and Voltage}

Each PPM within a current generator seeks a current/voltage (IV) operating point to satisfy the illumination conditions, operating temperature and voltage drops in the MCSA wiring and Mir power distribution cabling. PPMs in GS 1, panel 2, near the base of the MCSA produced a predicted $1.9 \mathrm{amps}$ at an operating voltage of 34 volts. There was a 5.5 volt total drop predicted between the PPM and the current regulator output. This voltage drop was split about evenly between MCSA wiring and Mir power distribution cabling.

By contrast, PPMs in GS 12 , panel 41 , at the tip of the MCSA produced 2 amps at an operating voltage of 38 volts.

At the tip of the array, PPMs operated much cooler than at the base thereby increasing their current output capability. However, the predicted MCSA wiring voltage losses were much greater, i.e. 6 volts, while the Mir cabling losses were only slightly greater, i.e. 3.5 volts, for a total voltage drop of 9.5 volts. For reference, the PPM design specification called for a 32.5-volt operating voltage and a 2.2-amp operating current at $56^{\circ} \mathrm{C}$. Cabling voltage drops increase the PPM operating voltage and decrease its output current which effectively translates into a loss in PPM and MCSA power output (see section 6.4).

\subsection{MCSA Power Output}

The MCSA output power through the orbit is shown in Figure 12 for the June and December test orbits. Predicted power values are shown: (1) as a summation of PPM power outputs, (2) as determined at the X1-X4 connectors at the base of the MCSA and (3) as delivered to the Mir power bus (i.e., the output of the current regulator). Data points are also shown for the power delivered to the Mir bus by summing measured generator currents and multiplying by the 28.5-volt Mir bus voltage.

The temporal power variation through the orbit follows, as expected, that of the current generators: that is, high initial values fall to a minimum at orbit noon followed by a modest recovery prior to entering orbit eclipse. In June, with 38 out of 84 total PPMs connected, the MCSA produced approximately $2.7 \mathrm{~kW}$ at the PPMs and delivered $2.2 \mathrm{~kW}$ to the Mir bus. This represents approximately a $20 \%$ loss in power attributable, in roughly equal parts, to MCSA wiring and Mir power cabling voltage losses. Similar results were found during the December test with all PPMs connected. During this test, the PPMs produced in excess of $6 \mathrm{~kW}$ of power while approximately $5 \mathrm{~kW}$ of power was delivered to Mir. For both the June and December tests, the predicted Mir bus power matched the data within the measurement error limits.

The power loss is a consequent of the low array voltage and retrofitted Mir power distribution cabling. The low array voltage leads to high currents and large voltage drops unless heavy conductor gauges are utilized. This is usually prohibited due to launch mass constraints or conductor flexibility requirements to permit folded array panel stowage. For comparison, the voltage loss on the $30 \mathrm{~kW}, 160$-volt ISS solar array wing is about $5 \%$ from the panels to the sequential shunt unit. However, the reader is reminded that Mir power cabling was designed and built over 10 years ago for Russian current generators. Therefore, to accommodate the MCSA, retrofitted cables had to follow circuitous paths leading to $\sim 50-\mathrm{m}$ cable sets and higher than desired resistance.

\subsection{Impact of Albedo Power Production}

Using a yearly average, global Earth albedo value of 0.27 , the predicted generator current output is enhanced by $3.5 \%$ over that predicted while ignoring albedo light generated current. This corresponds to $\sim 200$ watts more power delivered to the Mir bus for the December test. For a short-term, local terrain maximum albedo value of 0.54 , the generator current predicted is enhanced by $6 \%$ over the case that ignores albedo current generation. This corresponds to $\sim 350$ watts more power to the Mir bus. However, as albedo flux increases, absolute generator current output decreases. This suggests that the PPM temperature rise and concomitant loss in IV performance dominates the increased current production afforded by PPM back side albedo illumination.

Although back side albedo power enhancement can be computationally assessed on a yearly-average basis, it would be a challenging task for space station resource planners to utilize this power. The primary challenge arises from the fact that the local and global Earth albedo values are not known a priori. Thus, the degree of power enhancement can not be 
exploited during mission planning or execution phases. Furthermore, the albedo enhancement effect is diminished for high solar beta angle orbits as the array view factor to Earth decreases. Since both $\mathrm{Mir}$ and the planned ISS orbits are highly inclined, high beta angle orbits are encountered often.

\section{CONCLUDING REMARKS}

The MCSA was successfully designed, built and launched to Mir space station as one of the first ISS Phase 1 joint U.S.Russian programs. The MCSA has been performing very well on orbit since being deployed and activated in May 1996. MCSA performance measurement tests were conducted in June and December 1996. These data show the MCSA is meeting electrical performance specifications. The data correlated very favorably with computational predictions demonstrating MCSA performance was as expected and amenable to accurate analysis. This favorable comparison further bolsters confidence in the solar array performance modeling techniques used in forecasting ISS solar array performance that is an important part of ISS EPS utilization and mission operations planning.

There were no measurable indications of unexpected or precipitous MCSA performance degradation due to contamination or other causes after seven months of operation on orbit. Power delivered to the Mir bus was lower than desired as a consequence of the retrofitted power distribution cabling.

At least one more MCSA performance test is planned in December 1997, approximately 1 year after all generators were activated. These data are planned to be published in future paper.

\section{ACKNOWLEDEMENTS}

The authors wish to acknowledge and thank: the LockheedMartin Missiles \& Space Company, Sunnyvale California, for providing PPM IV data, Rocket Space Corporation - Energia, Moscow Russia, for providing the MCSA telemetry data and power distribution cable diagrams and Pozit, Moscow Russia, for measuring and providing the MCSA FCC resistances.

The authors also wish to acknowledge and thank Mr. Jeff Hojnicki of NASA LeRC for his expert FORTRAN programming assistance and his expert advice regarding electric power system analysis and modeling.

\section{REFERENCES}

Chau, M. T. and Brisco, H. N., 1995, "Elevated Temperature Testing of Mir 1 Cooperative Solar Array Photovoltaic Panel Module," IECEC paper no. AP-206, p. 357-362.

Fincannon, James, et al., 1996, "Load-Following Power Timeline Analyses for the International Space Station," $\underline{31 s t}$ Intersociety Energy Conversion Engineering Conference Proceedings, Washington, D.C..

Hoffman, D. J. and Scheiman, D. A., 1996, "Mir Cooperative Solar Array Project Accelerated Life Thermal Cycling Test," NASA TM-107197.

Hojnicki, J. S., 1991, "Computer Code Analyzes Electric Power System Performance," Research and Technology 1991 , NASA TM-105320, NASA Lewis Research Center, p. 130-131.

Hojnicki, J. S., et al., 1992, "Electric Power System Performance Model Enhanced," Research and Technology 1992, NASA TM-105924, NASA Lewis Research Center, pp. 134.
Hojnicki, J. S., et al., 1993, "Space Station Freedom Electrical Performance Model," 28th Intersociety Energy Conversion Engineering Conference Proceedings, Atlanta, Georgia.

Housten, S., et al., 1996, "The Mir Cooperative Solar Array Project," 47th Intersociety Astronautical Congress, paper no. IAA-96-IAA.6.1.106, Beijing, China.

Kerslake, Thomas W., et al., 1993, "System Performance Predictions for Space Station Freedom's Electrical Power System," 28th Intersociety Energy Conversion Engineering Conference Proceedings, Atlanta, Georgia.

Kerslake, Thomas W., et al., 1997, "Pre-Flight Dark Forward Electrical Testing of the Mir Cooperative Solar Array," 32nd Intersociety Energy Conversion Engineering Conference Proceedings, paper no. 97236, Honolulu, Hawaii.

Smith, C., 1986, "J2000.0," Highlights of Astronomy, Vol. 7 - Proceedings of the Nineteenth IAU General Assembly, Delhi, India, p. 73-76.

Wilkinson, William, 1995, "Mir 1 Cooperative Solar Array Photovoltaic Panel Production," IECEC paper no. AP-265, p. 353-355.

\begin{tabular}{|c|c|c|}
\hline Parameter & June 20,1996 & December 19,1996 \\
\hline Flight Attitude & $\begin{array}{c}\text { Solar Inertial } \\
\text { (IO-2) }\end{array}$ & $\begin{array}{c}\text { Solar Inertial } \\
\text { (IO-2) }\end{array}$ \\
\hline Mir Orbit Numbers & $3053,3054,3055$ & $1895,1896,1897$ \\
\hline $\begin{array}{l}\text { Krylov Angles, }^{\circ} \\
\text { Y } \\
\text { X } \\
\text { Z }\end{array}$ & $\begin{array}{r}-33.6 \pm 0.5 \\
+19.1 \pm 0.5 \\
+103.2 \pm 0.5\end{array}$ & $\begin{array}{l}-144.0 \pm 0.5 \\
-20.5 \pm 0.5 \\
-102.6 \pm 0.5\end{array}$ \\
\hline $\begin{array}{c}\text { Sun Angles, }^{\circ} \\
\text { X } \\
\text { Y } \\
\text { Z }\end{array}$ & $\begin{array}{r}26.3 \\
116.3 \\
89.5 \\
\end{array}$ & $\begin{array}{r}0.96 \\
89.04 \\
89.88 \\
\end{array}$ \\
\hline 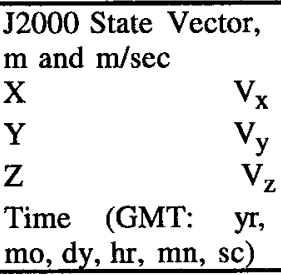 & 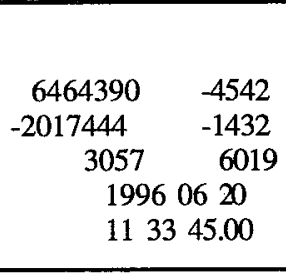 & 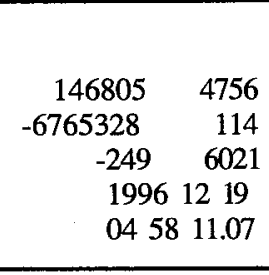 \\
\hline Orbit Altitude, nmi & 214.4 & 214.4 \\
\hline Orbit Inclination, ${ }^{\circ}$ & 51.6 & 51.6 \\
\hline Solar $\beta$ Angle, ${ }^{\circ}$ & +26.3 & -10.8 \\
\hline $\begin{array}{l}\text { Orbit Period, } \min \\
\text { Sun Time, min } \\
\text { Eclipse Time, min }\end{array}$ & $\begin{array}{l}92.5 \\
57.6 \\
34.9 \\
\end{array}$ & $\begin{array}{l}92.5 \\
56.6 \\
35.9 \\
\end{array}$ \\
\hline $\begin{array}{l}\text { Normalized } \\
\text { Solar Insolation } \\
\text { (Referenced to } \\
1371 \mathrm{~W} / \mathrm{m} 2 \text { ) } \\
\end{array}$ & 0.968 & 1.033 \\
\hline $\begin{array}{l}\text { Solar Array } \\
\text { Drive Angle, }\end{array}$ & $67.5 \pm 3$ & $90.0 \pm 3$ \\
\hline
\end{tabular}

Table 1. Mir Flight Attitude and Orbit Parameters 


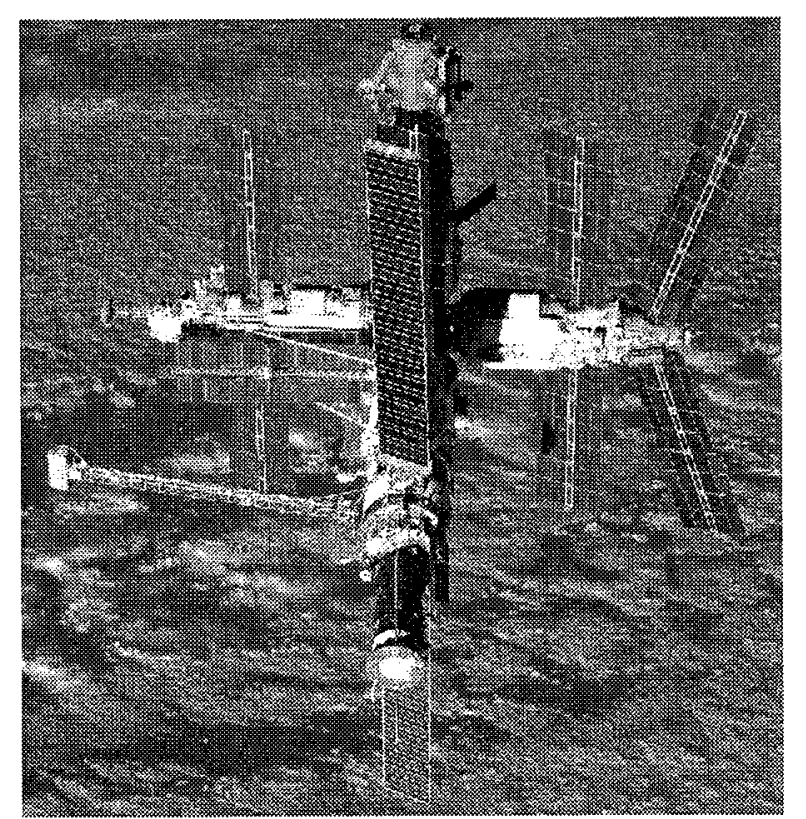

Figure 1. MCSA Deployed on Mir

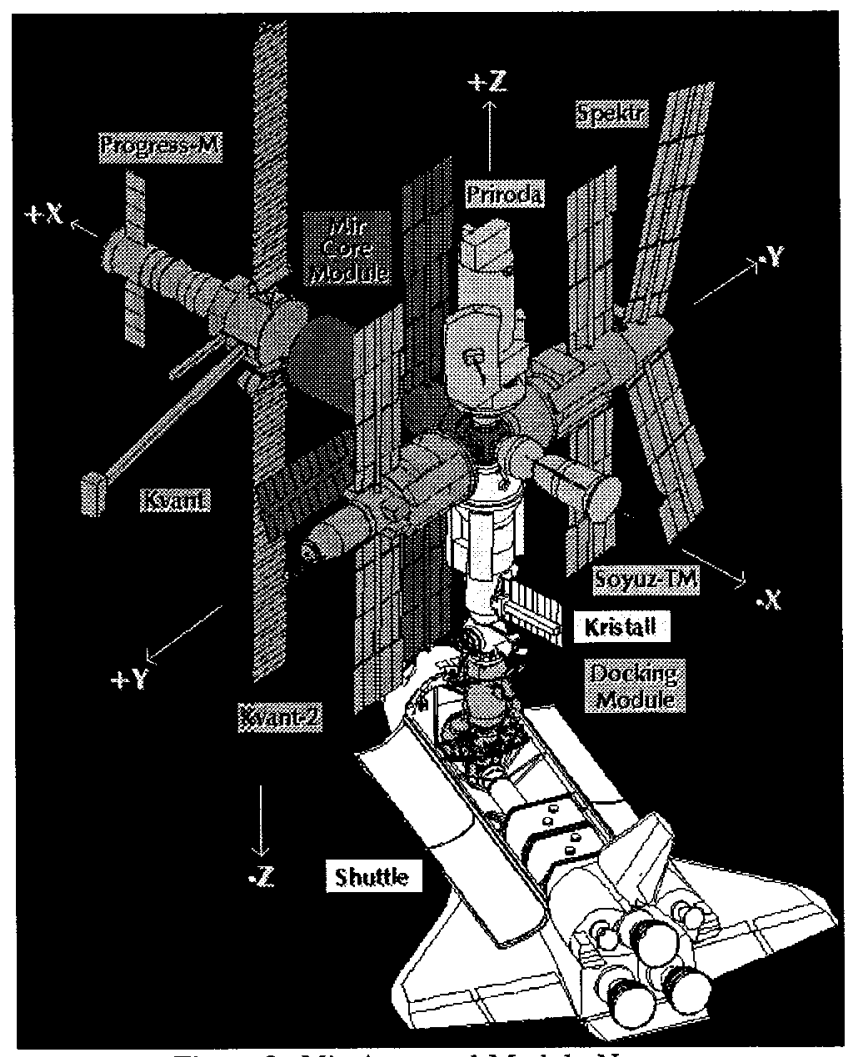

Figure 2. Mir Axes and Module Names

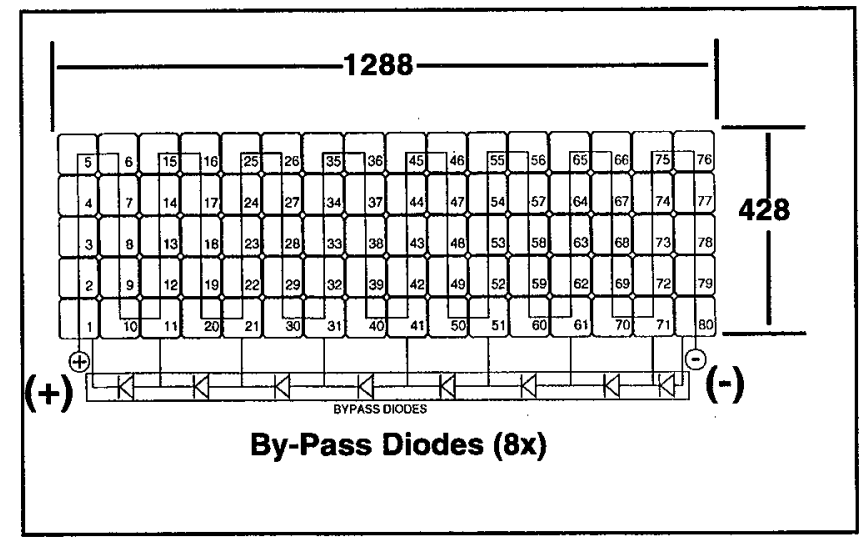

Figure 3. PPM Configuration (Dimensions in $\mathrm{mm}$ )

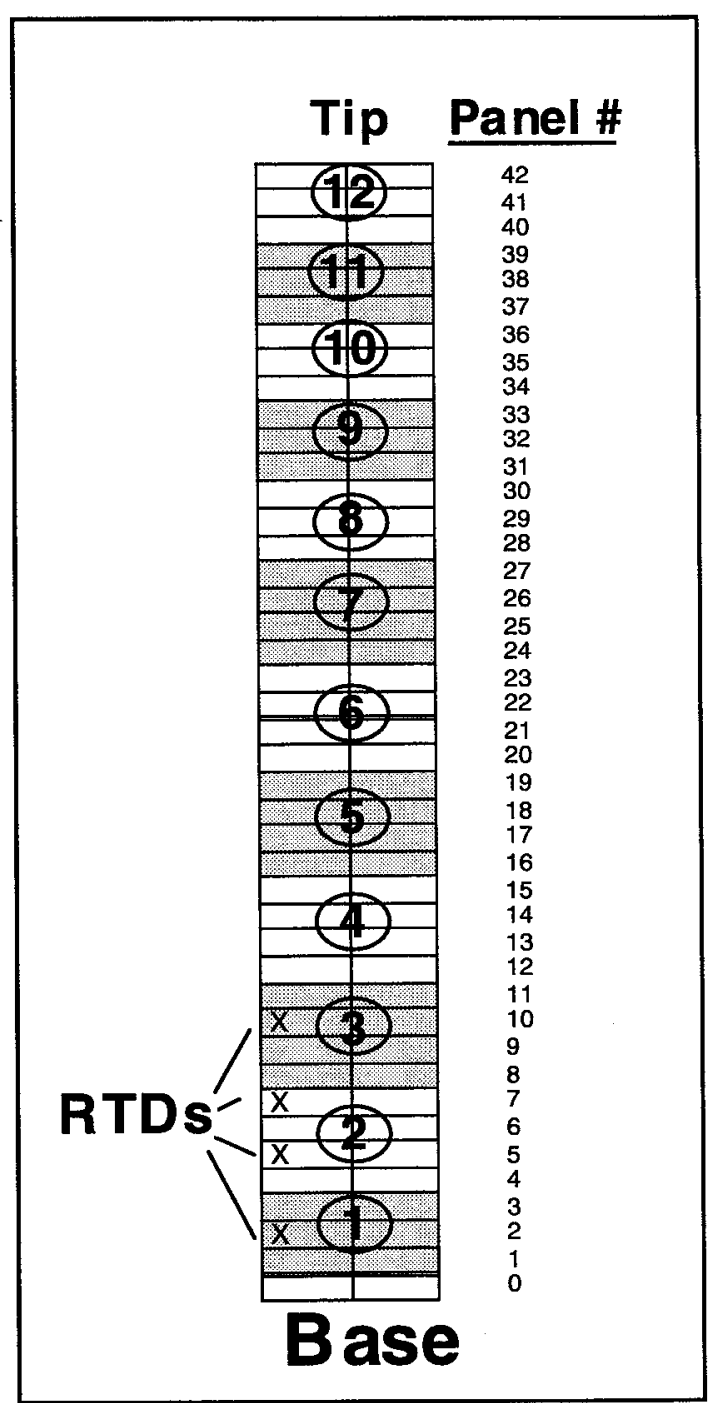

Figure 4. MCSA GS Grouping Schematic 


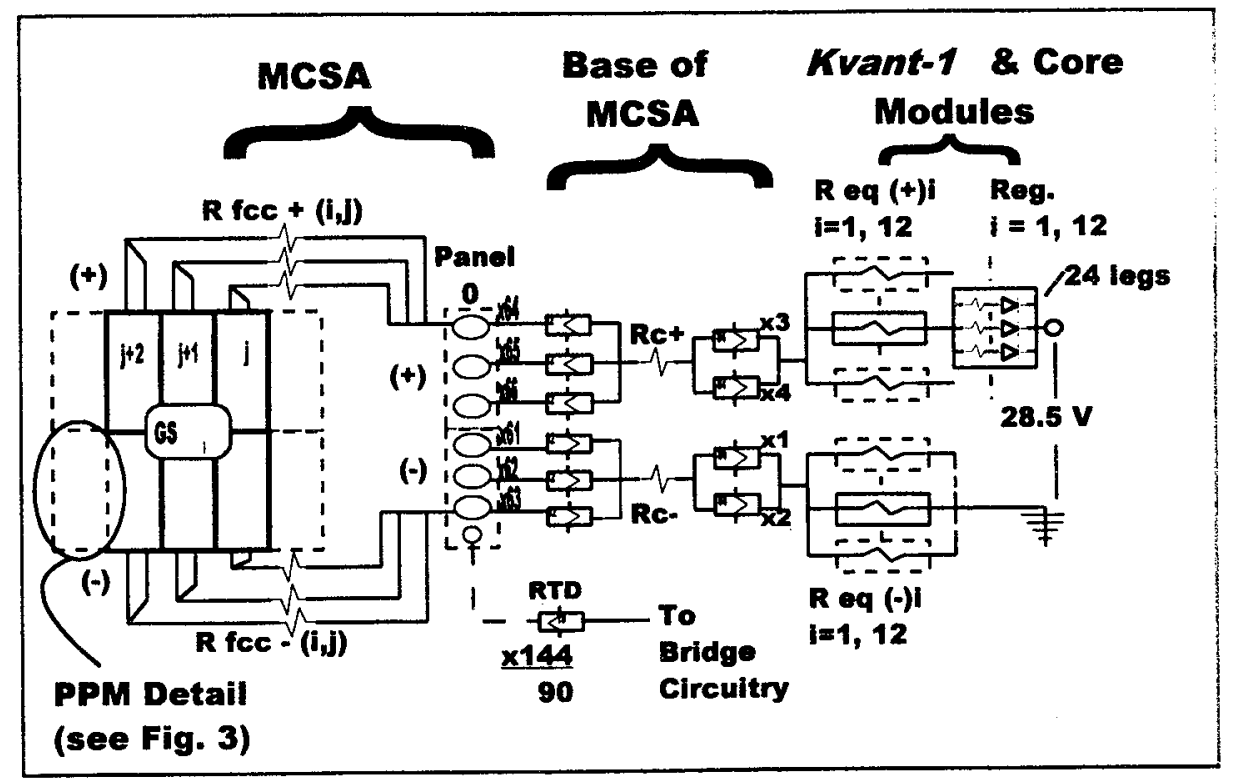

Figure 5.Circuit Schematic

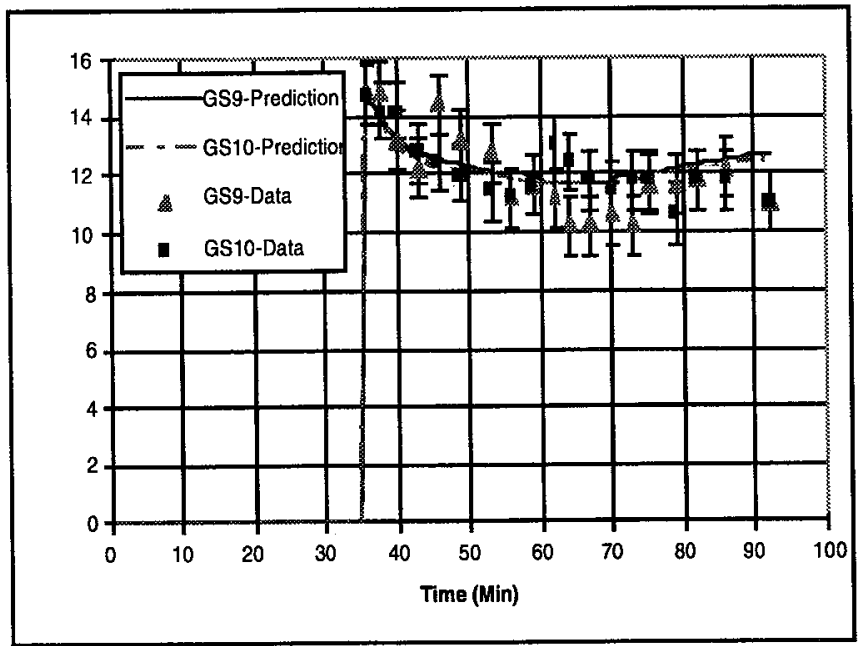

Figure 6. June GS 9 and 10 Current Output

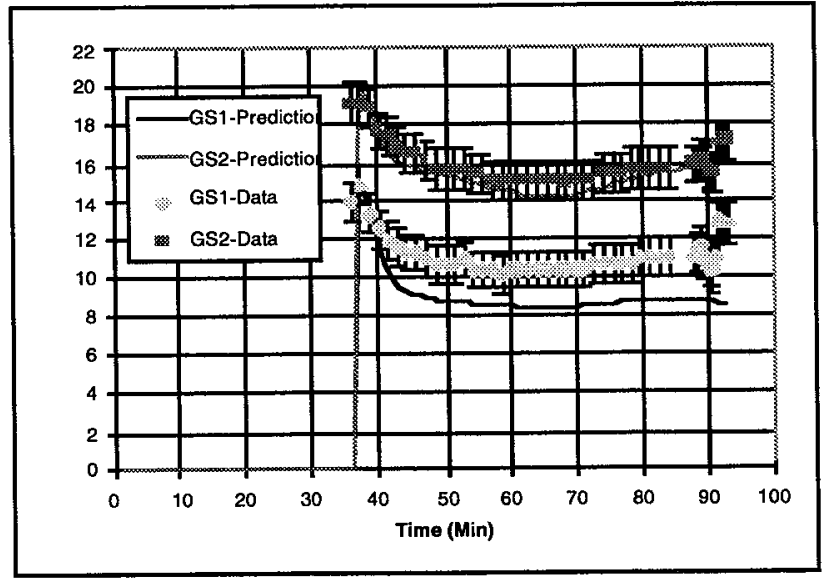

Figure 7. December GS 1 and 2 Current Output

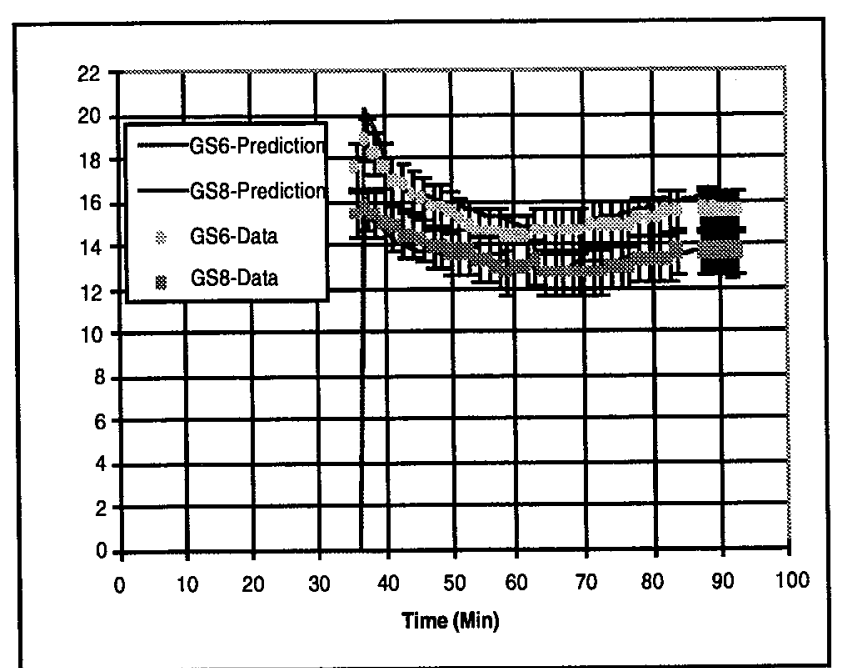

Figure 8. December GS 6 and 8 Current Output

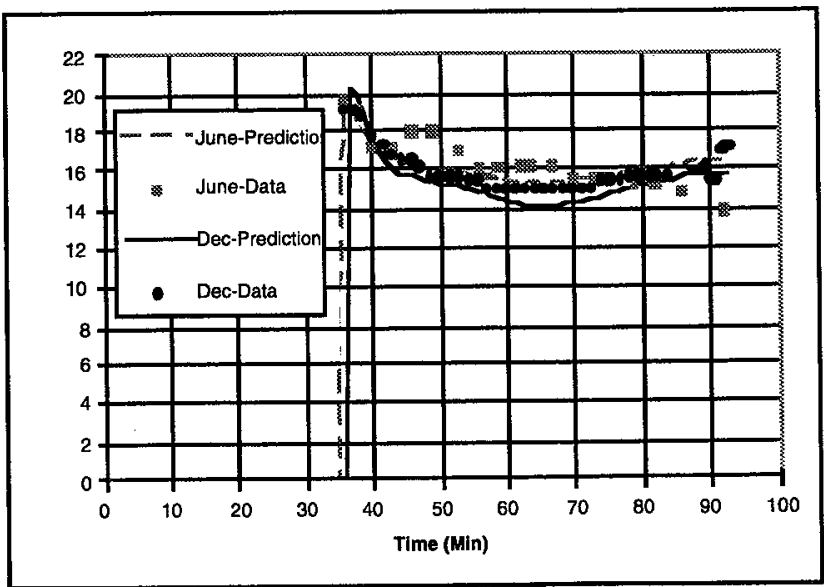

Figure 9. GS 2 Current Output in June and December 


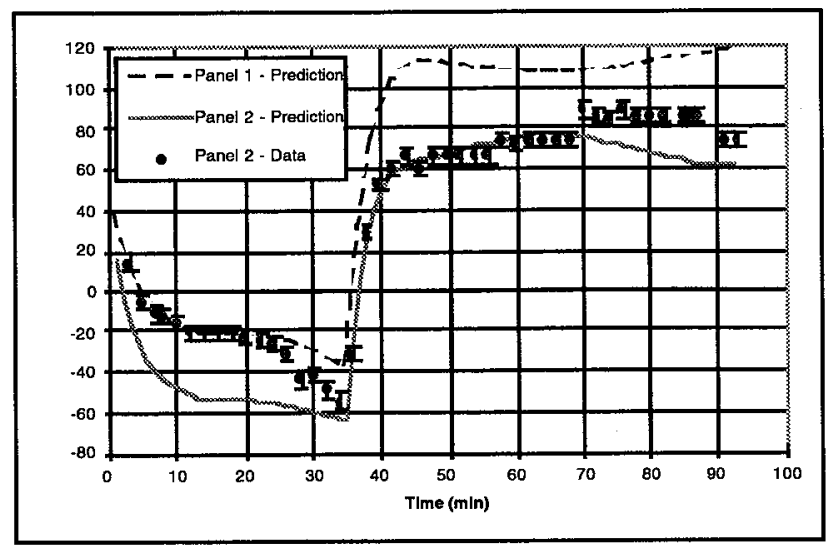

Figure 10. Panel 1 and 2 Temperatures in June

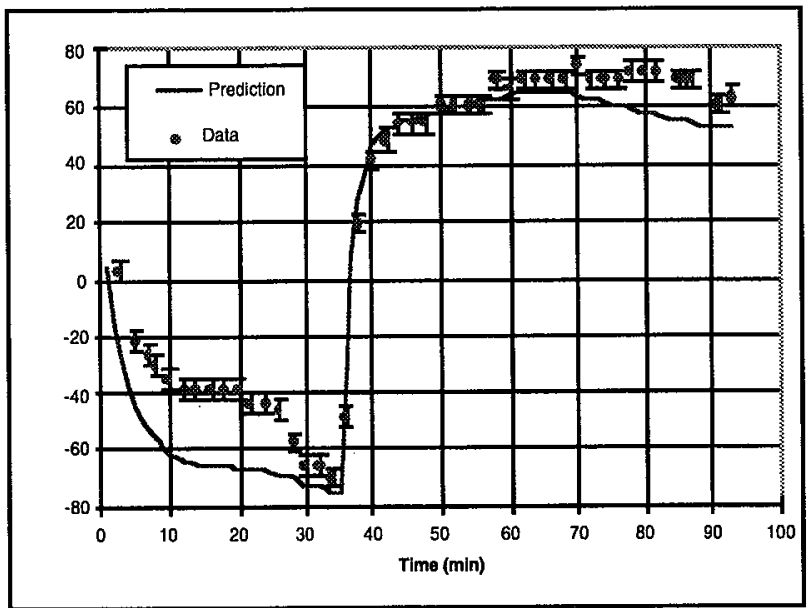

Figure 11. Panel 10 Temperatures in June

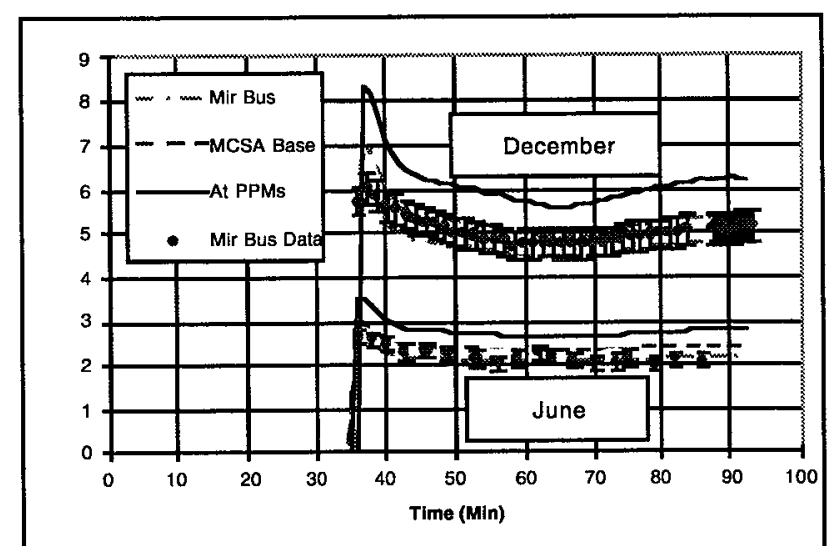

Figure 12. MCSA Total Output Power in June and December 
Public reporting burden for this collection of information is estimated to average 1 hour per response, including the time for reviewing instructions, searching existing data sources, gathering and maintaining the data needed, and completing and reviewing the collection of information. Send comments regarding this burden estimate or any other aspect of this collection of information, including suggestions for reducing this burden, to Washington Headquarters Services, Directorate for Information Operations and Reports, 1215 Je
Davis Highway, Suite 1204, Arlington, VA 22202-4302, and to the Office of Management and Budget, Paperwork Reduction Project (0704-0188), Washington, DC 20503.

\begin{tabular}{l|l|l|} 
Davis Highway, Suite 1204, Arlington, VA 22202-4302, and to the & 3. REPORT TYPE AND DATES COVERED \\
\hline 1. AGENCY USE ONLY (Leave blank) & 2. REPORT DATE
\end{tabular}

\begin{tabular}{|l|r|r|r|} 
July 1997 & Technical Memorandum \\
\hline
\end{tabular}

4. TITLE AND SUBTITLE

5. FUNDING NUMBERS

Mir Cooperative Solar Array Flight Performance Data and

Computational Analysis

6. AUTHOR(S)

WU-478-12-10

Thomas W. Kerslake and David J. Hoffman

7. PERFORMING ORGANIZATION NAME(S) AND ADDRESS(ES)

8. PERFORMING ORGANIZATION REPORT NUMBER

National Aeronautics and Space Administration

Lewis Research Center

Cleveland, Ohio 44135-3191

E-10804

9. SPONSORING/MONITORING AGENCY NAME(S) AND ADDRESS(ES)

10. SPONSORING/MONITORING AGENCY REPORT NUMBER

National Aeronautics and Space Administration

Washington, DC 20546-0001

NASA TM-107502

IECEC-97235

11. SUPPLEMENTARY NOTES

Prepared for the 32nd Intersociety Energy Conversion Engineering Conference cosponsored by AIChE, ANS, SAE, AIAA, ASME, and IEEE, Honolulu, Hawaii, July 27-August 1, 1997. Thomas W. Kerslake and David J. Hoffman, NASA Lewis Research Center.

Responsible person, Thomas W. Kerslake, organization code 6920, (216) 433-5373.

\begin{tabular}{|l|l|l|l|} 
12a. DISTRIBUTION/AVAILABILITY STATEMENT & 12b. DISTRIBUTION CODE
\end{tabular}

Unclassified - Unlimited

Subject Categories 18 and 20

This publication is available from the NASA Center for AeroSpace Information, (301) 621-0390.

13. ABSTRACT (Maximum 200 words)

The Mir Cooperative Solar Array (MCSA) was developed jointly by the United States (US) and Russia to provide approximately $6 \mathrm{~kW}$ of photovoltaic power to the Russian space station Mir. The MCSA was launched to Mir in November 1995 and installed on the Kvant-1 module in May 1996. Since the MCSA photovoltaic panel modules (PPMs) are nearly identical to those of the International Space Station (ISS) photovoltaic arrays, MCSA operation offered an opportunity to gather multi-year performance data on this technology prior to its implementation on ISS. Two specially designed test sequences were executed in June and December 1996 to measure MCSA performance. Each test period encompassed 3 orbital revolutions whereby the current produced by the MCSA channels was measured. The temperature of MCSA PPMs was also measured. To better interpret the MCSA flight data, a dedicated FORTRAN computer code was developed to predict the detailed thermal-electrical performance of the MCSA. Flight data compared very favorably with computational performance predictions. This indicated that the MCSA electrical performance was fully meeting pre-flight expectations. There were no measurable indications of unexpected or precipitous MCSA performance degradation due to contamination or other causes after 7 months of operation on orbit. Power delivered to the Mir bus was lower than desired as a consequence of the retrofitted power distribution cabling. The strong correlation of experimental and computational results further bolsters the confidence level of performance codes used in critical ISS electric power forecasting. In this paper, MCSA flight performance tests are described as well as the computational modeling behind the performance predictions.

14. SUBJECT TERMS

Solar arrays; Space stations; Orbital space tests; Flight tests; Performance prediction; Electric power; Performance tests; Mir Space Station

\begin{tabular}{|c|c|}
\hline 17. SECURITY CLASSIFICATION & 18. SECURITY CLASSIFICATION \\
OF REPORT & OF THIS PAGE \\
Unclassified & Unclassified
\end{tabular}

NSN 7540-01-280-5500
19. SECURITY CLASSIFICATION OF ABSTRACT

Unclassified
20. LIMITATION OF ABSTRACT 